Check for updates

Received 13th June 2018

Accepted 9th July 2018

rsc.li/rsc-advances
Cite this: RSC Adv., 2018, 8, 25351

DOI: $10.1039 / c 8 r a 05064 c$

\section{Preparation of a magnetic multiwalled carbon nanotubeapolydopamine/zeolitic imidazolate framework-8 composite for magnetic solid-phase extraction of triazole fungicides from environmental water samples}

\author{
Xiaodong Huang, ${ }^{a}$ Yanan Liu, ${ }^{\mathrm{b}}$ Guangyang Liu, ${ }^{\mathrm{b}}$ Lingyun $\mathrm{Li}^{\mathrm{b}}{ }^{\mathrm{b}}$ Xiaomin $\mathrm{Xu},{ }^{\mathrm{b}}$ \\ Shuning Zheng, ${ }^{\mathrm{b}}$ Donghui $\mathrm{Xu}^{\mathrm{b}}$ and Haixiang Gao (D) *a
}

\begin{abstract}
A novel magnetic zinc-based zeolitic imidazolate framework (MMP/ZIF-8) has been prepared using a magnetic multiwalled carbon nanotube@polydopamine nanocomposite as the magnetic core and support. It was then used as an adsorbent for magnetic solid-phase extraction of triazole fungicides from environmental water samples. Successful synthesis of MMP/ZIF-8 was confirmed by material characterization, and the results showed that the synthetic composite has a high Brunauer-EmmettTeller surface area $\left(141.56 \mathrm{~m}^{2} \mathrm{~g}^{-1}\right)$, large total pore volume $\left(0.636 \mathrm{~mL} \mathrm{~g} \mathrm{~g}^{-1}\right)$, and high superparamagnetism with a saturation magnetization of $44.1 \mathrm{emu}^{-1}$. To evaluate the extraction performance of MMP/ZIF-8, the main parameters that affect the extraction efficiency were optimized. Under the optimal conditions, the developed method shows good linearity $\left(R^{2} \geq 0.9915\right)$ in the concentration range 1-400 $\mu \mathrm{g} \mathrm{L}^{-1}$. Low limits of detection $\left(0.08-0.27 \mu \mathrm{g} \mathrm{L}^{-1}\right.$, signal/noise $\left.=3: 1\right)$ and good precision (intraday relative standard deviation $\leq 7.73 \%$, interday relative standard deviation $\leq$ 9.65\%) are also achieved. The developed method was applied for analysis of triazole fungicides in environmental water samples.
\end{abstract}

\section{Introduction}

Triazole fungicides are a class of systemic pesticides that can inhibit ergosterol, an essential component in fungal cell membranes, by influencing the cytochrome P450 enzyme activity to control soil-borne and foliar fungal pathogens. Because of their exceptional safety, high efficiency, and broad spectrum of biological activity, triazole fungicides are widely used to protect crops from fungal infections. ${ }^{1-3}$ Owing to their extensive use and accumulation over time, the residues of triazole fungicides can contaminate surrounding environmental components, including surface and groundwater, and inevitably result in potential risks to human health and ecosystems. Therefore, development of effective and sensitive techniques for determination of triazole fungicides in environmental water is vital. ${ }^{4,5}$ Sample preparation is the key procedure for analysis of pesticide residues. In recent years, various techniques have been developed to determine triazole fungicides in aqueous

${ }^{a}$ Department of Applied Chemistry, China Agricultural University, Beijing 100193, P. R. China. E-mail: hxgao@cau.edu.cn; Tel: +86 1062731991

${ }^{b}$ Institute of Vegetables and Flowers, Chinese Academy of Agricultural Sciences, Key Laboratory of Vegetables Quality and Safety Control, Ministry of Agriculture and Rural Affairs of China, Beijing 100081, P. R. China solutions, such as solid-phase extraction (SPE), solid-phase microextraction, and stir-bar sorptive extraction. ${ }^{6-9}$ Magnetic SPE (MSPE), which is an alternative to typical SPE, is based on application of a magnetic sorbent, enabling dispersion of a sorbent in a large sample volume, followed by efficient sorbent retrieval via an external magnetic field..$^{10}$ Because of the convenient and efficient magnetic separation process, MSPE can overcome the disadvantages of other methods, such as tedious or time consuming column packing and phase separation. ${ }^{11} \mathrm{~A}$ number of magnetic sorbents have been reported for MSPE, including direct application of magnetic nanoparticles (NPs) after surface functionalization and the use of composite/hybrid materials containing magnetic NPs combined with molecularly imprinted polymers, graphene, or metal-organic frameworks (MOFs). ${ }^{12}$

Zeolitic imidazolate frameworks (ZIFs), a new subclass of MOFs, are hybrid porous coordination polymers composed of tetrahedral transition metal ions (e.g., $\mathrm{Zn}$ and $\mathrm{Co}$ ) and imidazolate-type organic linkers. ${ }^{13}$ Because of their special features of microporosity, high surface area, and uniform structured cavities, ZIFs have many applications, such as chemical pollutant removal, chromatographic separation, and drug delivery. ${ }^{14-16}$ Several ZIFs have been used to prepare magnetic sorbents for MSPE, such as ZIF-7, ZIF-67, and ZIF- 
8. ${ }^{17-19}$ Among these ZIFs, the ZIF-8 framework ( $\mathrm{Zn}(2$ methylimidazole)), which is rich in carbon- and nitrogendoped ligands, can be easily prepared and is cost-effective, and it has been shown to be efficient for chemical pollutant adsorption and separation..$^{20-22}$ Moreover, ZIF composites prepared by integration with functional nanomaterials, such as polymers, carbon nanomaterials, and magnetic nanoparticles, have enhanced adsorption abilities and novel properties. $^{\mathbf{2 3 , 2 4}}$

Multiwalled carbon nanotubes (MWCNTs) are formed by seamlessly rolling up multiple layers of graphene sheets. Because of their excellent mechanical strength, high surface area, ability to establish $\pi-\pi$ interactions, stability, and capacity for functionalization, MWCNTs have been used as sorbents for several extraction techniques. ${ }^{25}$ Recently, MWCNTs have attracted widespread interest as magnetic adsorbents for MSPE of different analytes, such as antibiotics, estrogen, mycotoxins, metal ions, environmental pollutants, and pesticides. ${ }^{26-31}$ Magnetic MWCNTs have become the most intensively studied adsorbent material, and they show potential for sample preparation applications. ${ }^{32}$

In recent studies, polydopamine (PDA) has gained popularity for functionalizing MWCNTs for MSPE because of its extraordinary chemical and environmental stability and the ease of further modification. ${ }^{33}$ PDA, which is a mimic of the specialized adhesive foot protein secreted from marine mussels, has been widely used as a surface modification material to fabricate various nanocomposites for adsorption, catalysis, sensing, and drug delivery research. ${ }^{34,35}$ Moreover, some types of PDA-based ZIFs have recently been reported, indicating that PDA-based ZIFs have potential in many research fields, especially for sample preparation. ${ }^{19,36}$

A combination of $\mathrm{Fe}_{3} \mathrm{O}_{4}$ /MWCNT@PDA and ZIF-8 could improve the adsorption capacity of ZIF-8 for triazoles. In addition, the novel ZIF-8 composite based on $\mathrm{Fe}_{3} \mathrm{O}_{4}$ / MWCNT@PDA could possibly be used as an adsorbent for MSPE of triazole fungicides from environmental water samples. In this study, we designed a novel magnetic Zn-based ZIF composite using $\mathrm{Fe}_{3} \mathrm{O}_{4}$ /MWCNT@PDA as the magnetic kernel and support. The material was synthesized by organicinorganic coordination and used as an adsorbent for MSPE of five triazole fungicides from environmental water samples. This is the first report of preparation of magnetic ZIF-8 composites based on $\mathrm{Fe}_{3} \mathrm{O}_{4}$ /MWCNT@PDA nanocomposites and their use for determination of triazole fungicides in environmental water samples. The prepared magnetic composite was characterized, and several parameters that affect the extraction performance were optimized. The method was successfully applied to determine the presence of five triazole fungicides in real environmental water samples.

\section{Experimental}

\subsection{Reagents and materials}

Liquid pesticide standards of the triazole fungicides propiconazole, difenoconazole, epoxiconazole, fenbuconazole, and fluquinconazole at concentrations of $1000 \mathrm{mg} \mathrm{L}^{-1}$ were purchased from the Agro-Environmental Protection Institute, Ministry of Agriculture and Rural Affairs of China (Tianjin, China). A $20 \mathrm{mg} \mathrm{L}^{-1}$ standard mixture of the five triazole fungicides was prepared in methanol and stored at $-20{ }^{\circ} \mathrm{C}$ in the dark. High-performance liquid chromatography grade acetone, methanol, ethyl acetate, acetonitrile, and $n$-hexane were purchased from Sigma-Aldrich (St. Louis, USA). The MWCNTs (3-5 nm inner diameter (id), $50 \mu \mathrm{m}$ long, 95\% purity), analytical grade ferrous chloride tetrahydrate $\left(\mathrm{FeCl}_{2} \cdot 4 \mathrm{H}_{2} \mathrm{O}\right)$, ferric chloride hexahydrate $\left(\mathrm{FeCl}_{3} \cdot 6 \mathrm{H}_{2} \mathrm{O}\right)$, zinc sulfate heptahydrate $\left(\mathrm{ZnSO}_{4} \cdot 7 \mathrm{H}_{2} \mathrm{O}\right)$, 2-methylimidazole (2-MeIm), and ammonium hydroxide (mass fraction $28 \%$ ) were purchased from Aladdin Co. (Shanghai, China). Dopamine hydrochloride was purchased from Shanghai Yuanye Bio-Technology Co., Ltd. (Shanghai, China). Tris hydrochloride (proteomics grade) was supplied by Amresco (Washington, USA). Analytical grade ethanol and all of the other reagents were acquired from the Beijing Chemical Reagents Co. (Beijing, China).

\subsection{Apparatus and gas chromatography-tandem triple quadrupole mass spectrometry conditions}

The morphology of the materials was observed by scanning electron microscopy (SEM, JSM-6300, JEOL, Tokyo, Japan) equipped with energy dispersive spectrometry (EDS) and transmission electron microscopy (TEM, JEM-200CX, JEOL, Tokyo, Japan). The powder X-ray diffraction (XRD) measurements were performed with an X-ray powder diffractometer (D8 Advance, Bruker, Karlsruhe, Germany). The Fourier transform infrared (FT-IR) spectra were obtained with an FT-IR-8400 spectrometer (Shimadzu, Kyoto, Japan). The magnetic properties of all of the synthetic materials were determined by vibrating sample magnetometry (VSM, Lake Shore 7410, Columbus, USA). The Brunauer-Emmett-Teller (BET) surface area of the prepared composite was determined with an ASAP2020 porosimeter (Micromeritics, Norcross, USA). The nitrogen $\left(\mathrm{N}_{2}\right)$ adsorption and desorption isotherms were measured at $300 \mathrm{~K}$ using an ASAP2460 surface area and porosity analyzer (Micromeritics, Norcross, USA). The X-ray photoelectron spectroscopy (XPS, Waltham, USA) characterization was obtained on a Thermo Scientific Escalab 250Xi instrument.

Gas chromatography-tandem mass spectrometry (GC-MS/ MS) analysis was performed with a Shimadzu GC-2010 plus gas chromatograph coupled with an AOC-20s autosampler and a Shimadzu TQ8040 triple-quadrupole mass spectrometer (Shimadzu, Kyoto, Japan). A Rtx-5Ms capillary column $(0.25 \mathrm{~mm}$ (id) $\times 30 \mathrm{~m}, 0.25 \mu \mathrm{m}$ film thickness, Restek, Bellefonte, PA, USA) was used to separate the pesticides. Helium was used as the carrier gas at a constant flow rate of 1 $\mathrm{mL} \min ^{-1}$. The column temperature was initially held at $40{ }^{\circ} \mathrm{C}$ for $4 \mathrm{~min}$, increased to $125^{\circ} \mathrm{C}$ at $25^{\circ} \mathrm{C} \mathrm{min}{ }^{-1}$, ramped to $300{ }^{\circ} \mathrm{C}$ at $10{ }^{\circ} \mathrm{C} \mathrm{min}{ }^{-1}$, and held at $300^{\circ} \mathrm{C}$ for $6 \mathrm{~min}$. The total run time was $30.9 \mathrm{~min}$. The injection volume was $1.0 \mu \mathrm{L}$ in splitless mode. The specific multiple reaction monitoring (MRM) transitions for all five triazole fungicides and the other chromatographic parameters are given in Table 1. 
Table 1 Acquisition and chromatographic parameters for the five triazoles

\begin{tabular}{llllc}
\hline Triazoles & $t_{\mathrm{R}}(\mathrm{min})$ & MRM1 $(\mathrm{m} / \mathrm{z})$ & $\mathrm{CE}^{a}(\mathrm{eV})$ & MRM2 $(\mathrm{m} / \mathrm{z})$ \\
\hline Propiconazole-1 & 17.044 & $259.00>69.00$ & 14 & $259.00>191.00$ \\
Propiconazole-2 & 17.158 & $259.00>69.00$ & 14 & $259.00>191.00$ \\
Epoxiconazole & 17.701 & $192.00>138.00$ & 14 & $192.00>111.00$ \\
Fluquinconazole & 19.993 & $340.00>298.00$ & 20 & $340.00>313.00$ \\
Fenbuconazole & 20.363 & $198.10>129.10$ & 10 & $198.10>102.10$ \\
Difenoconazole-1 & 22.066 & $323.00>265.00$ & 14 & $323.00>202.00$ \\
Difenoconazole-2 & 22.135 & $323.00>265.00$ & 14 & $323.00>202.00$ \\
${ }^{a}$ CE means collision energy. & & & & 24 \\
\end{tabular}

\subsection{Preparation of $\mathrm{Fe}_{3} \mathrm{O}_{4} / \mathrm{MWCNT@PDA/ZIF-8}$}

2.3.1 Synthesis of $\mathrm{Fe}_{3} \mathrm{O}_{4} / \mathrm{MWCNTS}$ and $\mathrm{Fe}_{3} \mathrm{O}_{4} /$ MWCNT@PDA. The $\mathrm{Fe}_{3} \mathrm{O}_{4} / \mathrm{MWCNT}$ nanocomposites were synthesized according to a modified version of a previously reported chemical coprecipitation method. ${ }^{37}$ In brief, $0.2 \mathrm{~g}$ of MWCNTs was added to $240 \mathrm{~mL}$ of ultrapure water in a threenecked flask, and a homogeneous dispersion was obtained after $1 \mathrm{~h}$ of ultrasonic treatment. $\mathrm{FeCl}_{3} \cdot 6 \mathrm{H}_{2} \mathrm{O}(1.8 \mathrm{~g})$ and $\mathrm{FeCl}_{2} \cdot 4 \mathrm{H}_{2} \mathrm{O}(0.8 \mathrm{~g})$ solutions $(25 \mathrm{~mL})$ were then added to the flask, followed by vigorous stirring of the mixture with a mechanical stirrer under the protection of $\mathrm{N}_{2}$ at $80{ }^{\circ} \mathrm{C}$ for $30 \mathrm{~min}$. Ammonium hydroxide $(25 \%, 10 \mathrm{~mL})$ was then added dropwise, and the flask was stirred for another $30 \mathrm{~min}$. The black precipitates were collected by a magnet and washed three times with ultrapure water and ethanol. The synthetic nanomaterials were dried at $60{ }^{\circ} \mathrm{C}$ in a vacuum oven for $24 \mathrm{~h}$.

The $\mathrm{Fe}_{3} \mathrm{O}_{4} / \mathrm{MWCNT}$ composite was modified with PDA by a previously reported method. ${ }^{38}$ In brief, $\mathrm{Fe}_{3} \mathrm{O}_{4} / \mathrm{MWCNTs}(0.1 \mathrm{~g})$ was suspended in $100 \mathrm{~mL}$ of a Tris buffer solution (pH 8.5, 10 $\mathrm{mM}$ ), and then $0.4 \mathrm{~g}$ of dopamine hydrochloride was added. The polymerization reaction was performed under stirring for $6 \mathrm{~h}$. The mixture was then separated by an external magnet and washed three times with ultrapure water and ethanol. The assynthesized $\mathrm{Fe}_{3} \mathrm{O}_{4} /$ MWCNT@PDA material was dried at $60{ }^{\circ} \mathrm{C}$ in a vacuum oven for $24 \mathrm{~h}$.

2.3.2 Synthesis of MMP/ZIF-8. The MMP/ZIF-8 composite was fabricated by a previously reported method with slight modification. ${ }^{22}$ The synthesis process of MMP/ZIF-8 was as follows: first, after washing three times with ultrapure water and ethanol, $\mathrm{Fe}_{3} \mathrm{O}_{4} / \mathrm{MWCNT}$ @PDA was dispersed in $240 \mathrm{~mL}$ of ultrapure water/ethanol $(1: 1, \mathrm{v} / \mathrm{v})$, and $0.26 \mathrm{~g}$ of $\mathrm{ZnSO}_{4} \cdot 7 \mathrm{H}_{2} \mathrm{O}$ was added. The mixture was stirred for $1.5 \mathrm{~h}$. To this solution, $20 \mathrm{~mL}$ of an aqueous ethanol solution of 2 -MeIm $(0.84 \mathrm{~g})$ was added and the solution was stirred for $8 \mathrm{~h}$. All of these synthetic processes were performed at room temperature. Finally, the MMP/ZIF-8 product was collected by magnetic separation and washed three times with ultrapure water and ethanol. The final product was dried at $60{ }^{\circ} \mathrm{C}$ in a vacuum oven for $24 \mathrm{~h}$.

\subsection{MSPE procedure}

The workflow of the MSPE procedure is shown in Fig. 1. First, $10 \mathrm{mg}$ of the adsorbent material was added to $5 \mathrm{~mL}$ of a sample solution in a $10 \mathrm{~mL}$ centrifuge tube. The extraction process was performed by vortexing the mixture for $2 \mathrm{~min}$. An external magnet was then placed on the outside wall of the tube to collect the adsorbent, and the clear supernatant was discarded. Subsequently, $0.5 \mathrm{~mL}$ of acetone was added to the tube and vortexed for $3 \mathrm{~min}$ to elute the analytes from the magnetic material. After the MMP/ZIF-8 composite was collected, the supernatant desorption solution was transferred to another $10 \mathrm{~mL}$ centrifuge tube. The same desorption procedure was performed two more times. Finally, the combined desorbed elution samples were evaporated until dry under a gentle stream of $\mathrm{N}_{2}$ at $40^{\circ} \mathrm{C}$. The residue was redissolved in $0.5 \mathrm{~mL}$ of acetone, and $1 \mu \mathrm{L}$ of this solution was analyzed by GC-MS/MS.

\subsection{Sample preparation}

Four water samples were analyzed. The tap water sample was obtained from the tap in the laboratory, the river water sample was collected from the Liangshui River in Beijing, the well water sample was collected from the Yanqing District of Beijing, and the pond water sample was collected from a pond in Langfang City, Hebei Province. All of the samples were filtered through a $0.45 \mu \mathrm{m}$ polytetrafluoroethylene membrane filter and stored in brown glass bottles at $4{ }^{\circ} \mathrm{C}$.

\section{Results and discussion}

\subsection{Characterization of MMP/ZIF-8}

Successful preparation of MMP/ZIF-8 was confirmed by XRD and FT-IR spectroscopy. The XRD patterns of $\mathrm{Fe}_{3} \mathrm{O}_{4}, \mathrm{Fe}_{3} \mathrm{O}_{4} /$ MWCNTs, $\mathrm{Fe}_{3} \mathrm{O}_{4} /$ MWCNTs@PDA, and MMP/ZIF-8 are shown in Fig. 2A. The diffraction patterns of MMP/ZIF-8 is similar to the characteristic peaks appearing at 21.1, 35.2, 41.5, 63.2, 67.7, and 74.6 of $\mathrm{Fe}_{3} \mathrm{O}_{4}$, indicates that the crystalline structure of $\mathrm{Fe}_{3} \mathrm{O}_{4}$ was retained in MMP/ZIF-8 after modification. ${ }^{39}$ According to the literature, the formation of $\mathrm{MMP} / \mathrm{ZIF}-8$ was confirmed by XRD with diffraction peaks in the range $10-25^{\circ} .{ }^{40}$ The FT-IR spectra of the as-synthesized materials are shown in Fig. 2B. The adsorption band at $569 \mathrm{~cm}^{-1}$ for MMP/ZIF-8 can be attributed to the stretching vibration of $\mathrm{Fe}-\mathrm{O}$, which proves that $\mathrm{Fe}_{3} \mathrm{O}_{4}$ is successfully combined into the composite. The band at $1528 \mathrm{~cm}^{-1}$ corresponds to in-plane bending of $\mathrm{CH}_{2}$ in the MWCNTs. The adsorption bands at 1578, 1382, and $1208 \mathrm{~cm}^{-1}$ correspond to the stretching vibrations of $\mathrm{C}=\mathrm{C}, \mathrm{N}-\mathrm{H}$, and $\mathrm{C}-\mathrm{O}$ from PDA, respectively. The bands at 416, 1426, and 820$1306 \mathrm{~cm}^{-1}$ can be attributed to the $\mathrm{Zn}-\mathrm{N}$ stretching vibration, 


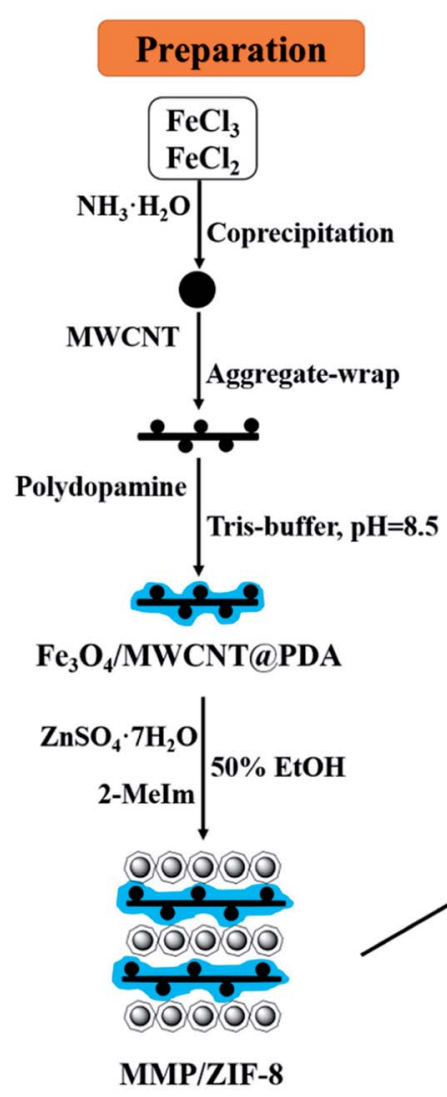

$\mathrm{Fe}_{3} \mathrm{O}_{4}$

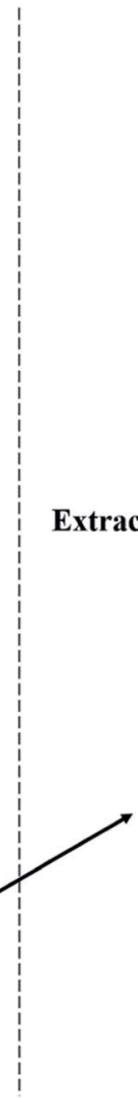

(c) ZIF-8

\section{Determination}
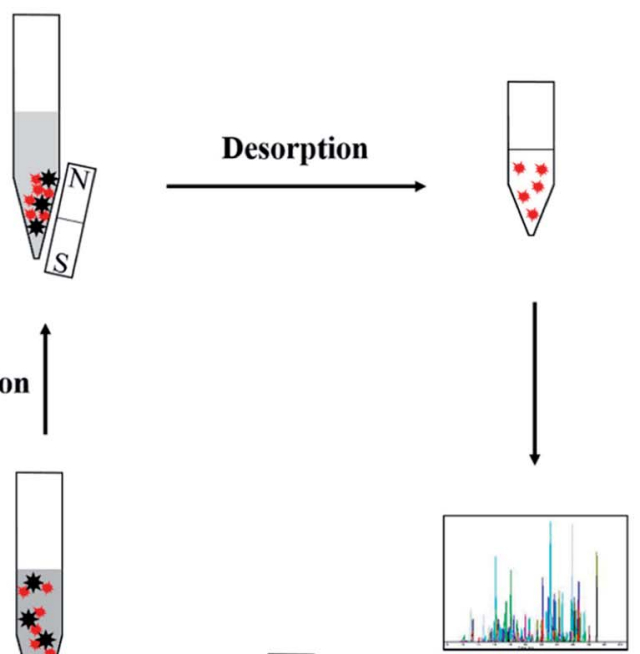

GC-MS/MS analysis
Water sample
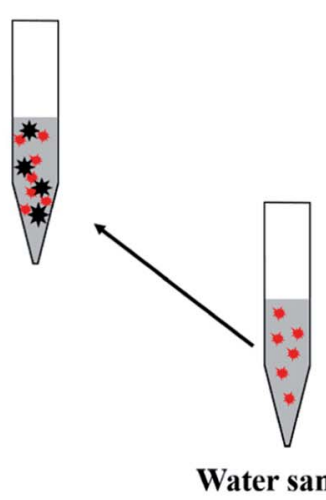

\section{Triazole fungicide $\quad$ MMP/ZIF-8}

Fig. 1 Schematic diagram of the synthetic route to prepare MMP/ZIF-8 and the MSPE steps for triazole fungicide analysis.

and the adsorption band at $813 \mathrm{~cm}^{-1}$ corresponds to $\mathrm{C}-\mathrm{N}$, which is characteristic of an imidazole ring. All of the XRD patterns and adsorption bands in the FT-IR spectra indicate that the MMP/ZIF-8 composite was successfully synthesized.
The morphologies of $\mathrm{Fe}_{3} \mathrm{O}_{4}, \quad \mathrm{Fe}_{3} \mathrm{O}_{4} / \mathrm{MWCNTs}, \quad \mathrm{Fe}_{3} \mathrm{O}_{4} /$ MWCNT@PDA, and MMP/ZIF- 8 were characterized by SEM and TEM. As shown in Fig. 3A, the $\mathrm{Fe}_{3} \mathrm{O}_{4}$ nanospheres are slightly aggregated with an average diameter of approximately $10 \mathrm{~nm}$.
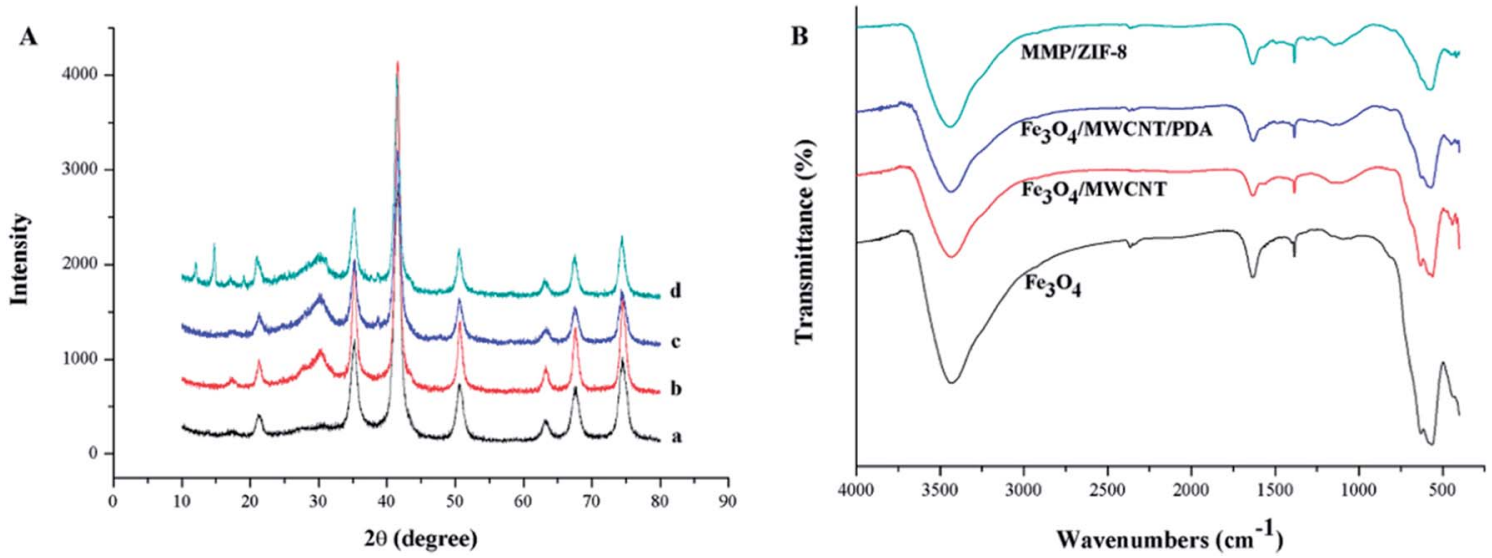

Fig. 2 (A) XRD patterns of (a) $\mathrm{Fe}_{3} \mathrm{O}_{4}$, (b) $\mathrm{Fe}_{3} \mathrm{O}_{4} /$ MWCNTs, (c) $\mathrm{Fe}_{3} \mathrm{O}_{4} /$ MWCNTaPDA, and (d) MMP/ZIF-8. (B) FT-IR spectra of the synthetic materials. 


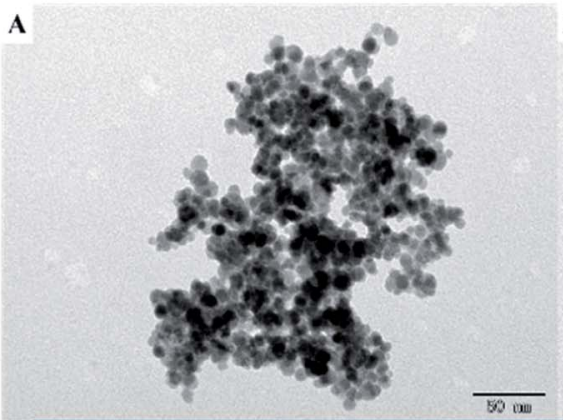

B

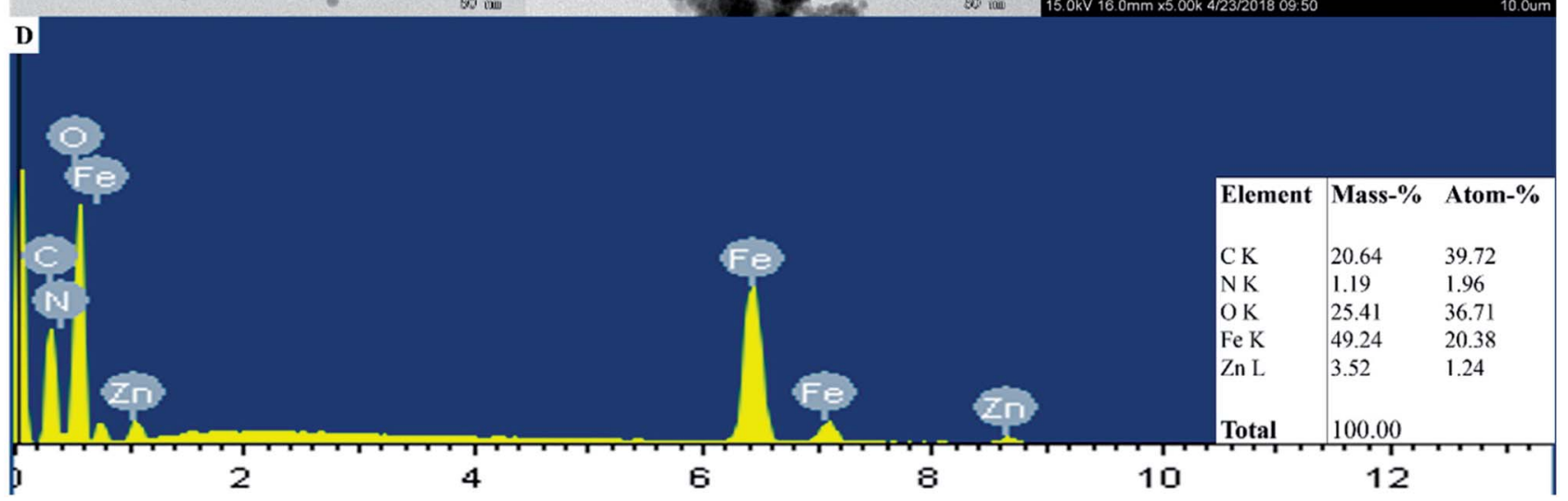

Fig. 3 TEM images of (A) $\mathrm{Fe}_{3} \mathrm{O}_{4}$ and (B) $\mathrm{Fe}_{3} \mathrm{O}_{4} / M W C N T$ (aPDA. (C) SEM image and (D) EDS analysis of MMP/ZIF-8.

Fig. 3B shows that the $\mathrm{Fe}_{3} \mathrm{O}_{4}$ nanoparticles are well deposited on the surface of the MWCNTs, and PDA is located on the surface of $\mathrm{Fe}_{3} \mathrm{O}_{4}$ /MWCNTs. Fig. 3C shows that the MMP/ZIF-8 composite exhibits a highly porous block-shaped structure, suggesting that the prepared material has good potential adsorption properties. The EDS spectrum of MMP/ZIF-8 (Fig. 3D) shows the composition and distribution of atoms on the material surface. The results show that the molar percentages of $\mathrm{C}, \mathrm{N}, \mathrm{O}, \mathrm{Fe}$, and $\mathrm{Zn}$ in MMP/ZIF-8 are $20.64 \%, 1.19 \%$, $25.41 \%, 49.24 \%$, and $3.52 \%$, respectively.

In this study, XPS analysis was conducted to measure the elemental composition of the synthesized MMP/ZIF-8. As can be seen from Fig. 4A, the binding energy of $1022.08 \mathrm{eV}$ corresponded to the $\mathrm{Zn} 2 \mathrm{p}_{3 / 2}$, while $\mathrm{Zn} 2 \mathrm{p}_{1 / 2}$ was located at $1045.08 \mathrm{eV}$. The binding energy distance between these two lines was $23 \mathrm{eV}$, indicating that the $\mathrm{Zn}$ ions were +2 states, and the composites are covered by ZIF-8. ${ }^{\mathbf{4 1 , 4 2}}$

The magnetic properties of the prepared materials were investigated by VSM, and the results are shown in Fig. 4B. The magnetic hysteresis loops of the four types of magnetic materials show that both the remanence and coercivity values are zero, indicating typical superparamagnetism and that the material can be rapidly separated with a magnet. The saturation magnetization values of $\mathrm{Fe}_{3} \mathrm{O}_{4}, \mathrm{Fe}_{3} \mathrm{O}_{4} / \mathrm{MWCNTs}, \mathrm{Fe}_{3} \mathrm{O}_{4} /$ MWCNT@PDA, and MMP/ZIF-8 are 68.8, 58.9, 45.9, and 44.1 emu $^{-1}$, respectively. Furthermore, the well-dispersed MMP/ ZIF-8 composite particles rapidly accumulated on the wall of the vial in a short time (approximately $10 \mathrm{~s}$ ) with the aid of an external magnet, which further indicates its potential as a MSPE sorbent.
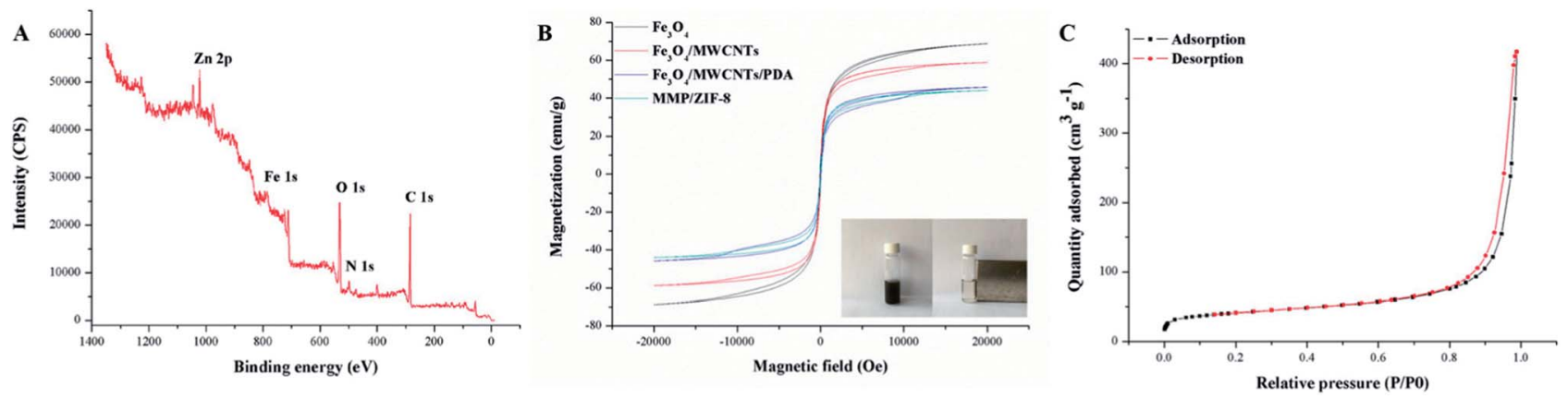

Fig. 4 (A) XPS spectra of MMP/ZIF-8; (B) magnetic curves of the synthetic materials; and (C) $\mathrm{N}_{2}$ adsorption-desorption isotherms. 

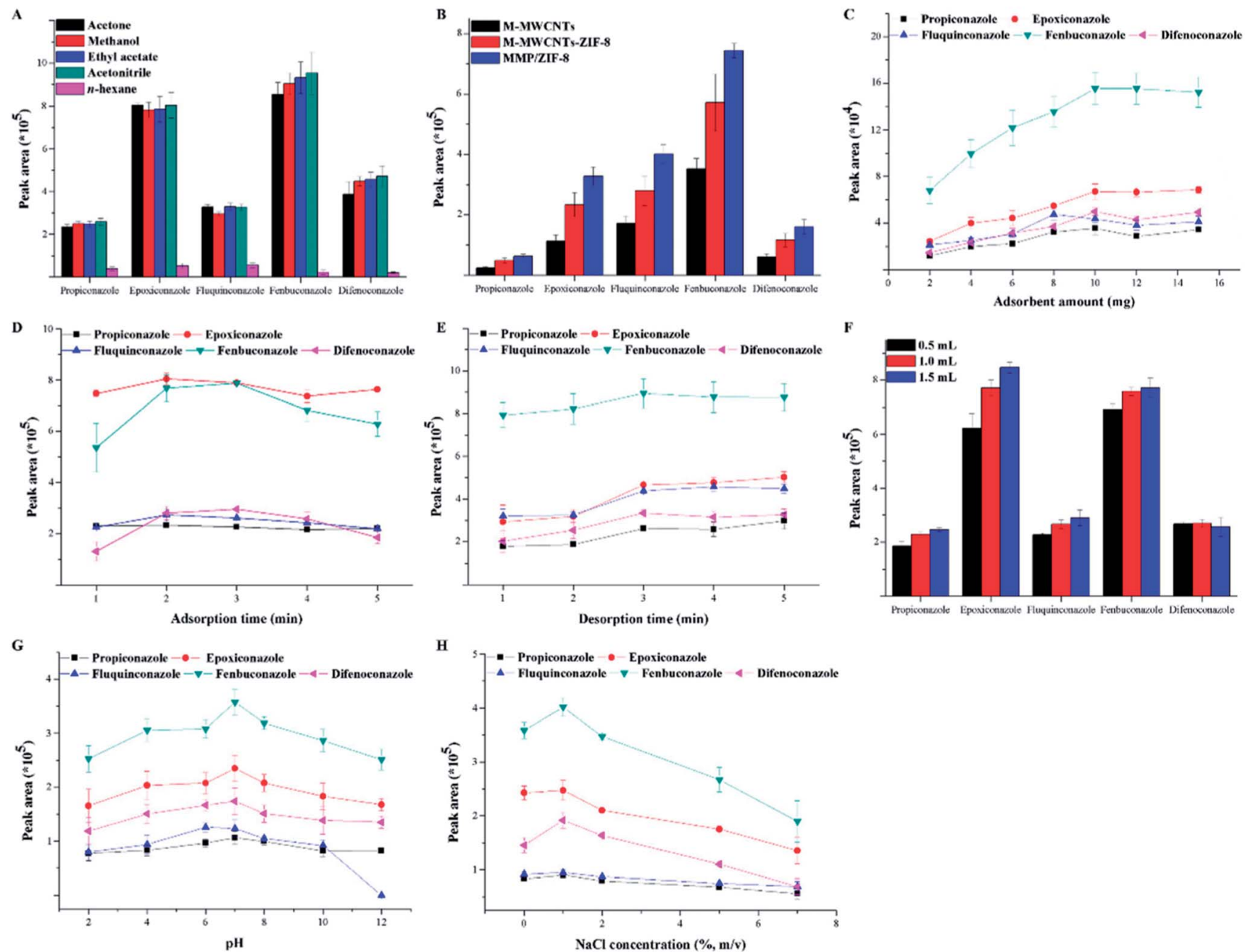

Fig. 5 Effect of different parameters on the extraction efficiency of triazoles from water: (A) desorption solvent, (B) type of adsorbent, (C) amount of adsorbent, (D) adsorption time, (E) desorption time, (F) desorption solvent volume, (G) sample pH, and (H) salt addition.

The pore properties of the MMP/ZIF-8 material were investigated by $\mathrm{N}_{2}$ adsorption-desorption, and the results are shown in Fig. 4C. The general shapes of the $\mathrm{N}_{2}$ adsorptiondesorption isotherms show that $\mathrm{N}_{2}$ adsorption increases at low relative pressures $\left(P / P_{0}<0.8\right)$ and steeply increases at high relative pressures $\left(0.8<P / P_{0}<1.0\right)$, indicating the coexistence of different pores ranging from meso- to macropores. ${ }^{43}$ The BET surface area and pore volume of MMP/ZIF-8 are $141.56 \mathrm{~m}^{2} \mathrm{~g}^{-1}$ and $0.636 \mathrm{~mL} \mathrm{~g}^{-1}$, respectively. The results suggest that MMP/ZIF-8 has a high surface area and large total pore volume, which will both facilitate adsorption of triazole fungicides.

\subsection{Optimization of the MSPE parameters}

The parameters that affect the adsorption and desorption performance of MSPE for triazoles, including the eluent type

Table 2 Analytical parameters of MMP/ZIF-8 as an adsorbent for MSPE of the five triazoles from ultrapure water samples

\begin{tabular}{|c|c|c|c|c|c|c|}
\hline \multirow[b]{2}{*}{ Triazoles } & \multirow[b]{2}{*}{ Calibration equation } & \multirow[b]{2}{*}{$\begin{array}{l}\text { Linear range } \\
\left(\mu g \mathrm{~L}^{-1}\right)\end{array}$} & \multirow[b]{2}{*}{$R^{2}$} & \multirow[b]{2}{*}{$\begin{array}{l}\text { LOD } \\
\left(\mu g \mathrm{~L}^{-1}\right)\end{array}$} & \multicolumn{2}{|c|}{$\operatorname{RSD}^{a}(\%)(n=6)$} \\
\hline & & & & & Intraday & Interday \\
\hline Propiconazole & $Y=340591 X+306$ & $1-400$ & 0.9967 & 0.22 & 7.73 & 9.65 \\
\hline Epoxiconazole & $Y=1834222 X+2859$ & $1-400$ & 0.9915 & 0.08 & 4.41 & 5.62 \\
\hline Fluquinconazole & $Y=816474 X+862$ & $1-400$ & 0.9926 & 0.10 & 4.59 & 5.70 \\
\hline Fenbuconazole & $Y=1863833 X+5496$ & $1-400$ & 0.9965 & 0.08 & 4.04 & 4.43 \\
\hline Difenoconazole & $Y=220839 X+1470$ & $1-400$ & 0.9948 & 0.27 & 7.34 & 8.98 \\
\hline
\end{tabular}

${ }^{a}$ The RSDs were determined by performing six replicate analyses of spiked samples with $10 \mu \mathrm{g} \mathrm{L}^{-1}$ of each triazole. 


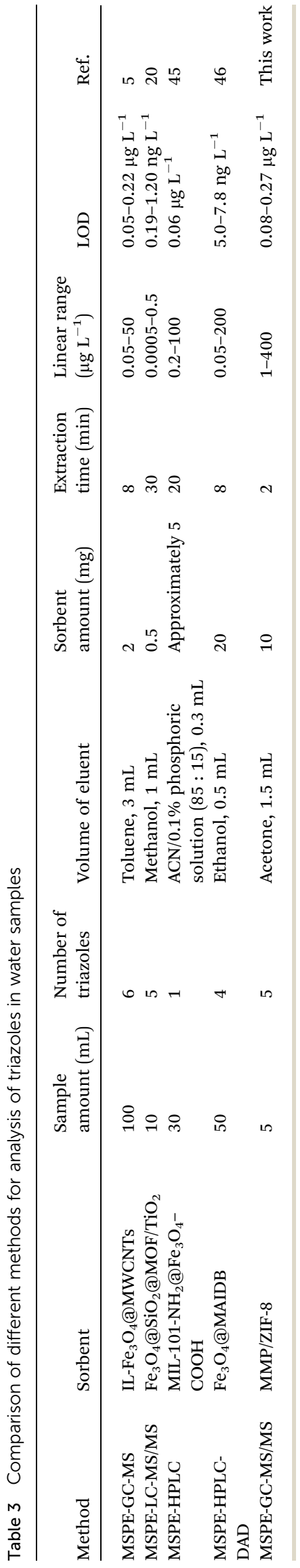

and volume, sorbent type and amount, extraction time, and desorption time, were investigated by single-factor experiments following a step-by-step procedure.

The desorption solvent is crucial for the MSPE extraction efficiency. Therefore, several types of desorption solvents were investigated: acetone, methanol, ethyl acetate, acetonitrile, and $n$-hexane. As shown in Fig. 5A, acetonitrile shows in the best extraction efficiency, and it was used as the desorption solvent for the following experiments.

The adsorption capabilities of $\mathrm{Fe}_{3} \mathrm{O}_{4} /$ MWCNTs, $\mathrm{Fe}_{3} \mathrm{O}_{4} /$ MWCNT/ZIF-8, and MMP/ZIF-8 for the five triazoles were investigated. As shown in Fig. 5B, the MMP/ZIF-8 sorbent exhibits the highest adsorption capacity for the triazoles, which can be ascribed to the higher surface area of MMP/ZIF- 8 and the PDA coating. Owing to the PDA coating on the surface of $\mathrm{Fe}_{3} \mathrm{O}_{4} /$ MWCNTs, various interactions between the sorbent and analytes are enhanced, such as $\pi-\pi$ interactions, hydrophobic interactions, and hydrogen bond formation for sorption of the target analytes. ${ }^{44}$ Therefore, MMP/ZIF-8 was selected as the adsorbent for the following experiments.

The effect of the sorbent amount on the extraction efficiency was investigated using MMP/ZIF-8 amounts ranging from 2 to $15 \mathrm{mg}$. As shown in Fig. 5C, the extraction efficiency continuously increases as the adsorbent amount increases from 2 to $10 \mathrm{mg}$, but the efficiency slightly decreases with a further increase in the sorbent dosage, indicating that $10 \mathrm{mg}$ is the optimal sorbent amount for extraction of triazoles. Therefore, $10 \mathrm{mg}$ of MMP/ZIF-8 was used for the following experiments.

The adsorption time can affect the adsorption equilibrium between the sample solution and adsorbent. To investigate the influence of the adsorption time on the extraction efficiency, five different vortex times in the range 1-5 min were investigated (Fig. 5D). The results suggest that $2 \mathrm{~min}$ is sufficient and further increasing the vortex time does not improve the extraction efficiency. Thus, 2 min was chosen as the optimal adsorption time.

To study the effect of the desorption time on the MSPE efficiency, experiments were performed with vortex desorption times of 1-5 min (Fig. 5E). Satisfactory extraction efficiency is achieved at $3 \mathrm{~min}$ and remains constant thereafter. Considering the operational efficiency, 3 min was chosen as the optimal desorption time.

To investigate the effect of the desorption solvent volume on the extraction efficiency, $0.5 \mathrm{~mL}$ of eluent with $3 \mathrm{~min}$ vortex desorption was used to elute the analytes one to three times. The results are shown in Fig. 5F. The optimal extraction efficiency is achieved when the analytes are eluted three times. Hence, the desorption solvent volume was set to $1.5 \mathrm{~mL}$ for the remainder of the experiments.

Owing to the probable alteration of the chemical forms of the analytes and/or the surface charge of the adsorbent, the sample solution $\mathrm{pH}$ always plays an important role in MSPE procedures. Therefore, the effect of the solution $\mathrm{pH}$ on the extraction performance of triazoles was investigated by adjusting the $\mathrm{pH}$ from 2 to 12 with $\mathrm{HCl}$ or $\mathrm{NaOH}$. As shown in Fig. 5G, the extraction performance at neutral $\mathrm{pH}$ is better than under acidic 
Table 4 Analytical results for determination of triazoles in real water samples

\begin{tabular}{|c|c|c|c|c|c|c|}
\hline \multirow[b]{3}{*}{ Matrix } & \multirow[b]{3}{*}{ Analyte } & \multicolumn{5}{|c|}{ Spiked concentration $\left(\mu \mathrm{g} \mathrm{L}^{-1}, n=3\right)$} \\
\hline & & \multirow{2}{*}{$\frac{0}{\text { Found }}$} & \multicolumn{2}{|l|}{10} & \multicolumn{2}{|l|}{100} \\
\hline & & & Recovery (\%) & RSD (\%) & Recovery (\%) & $\operatorname{RSD}(\%)$ \\
\hline \multirow[t]{5}{*}{ Tap water } & Propiconazole & $\mathrm{ND}^{a}$ & 87.1 & 4.0 & 91.5 & 1.3 \\
\hline & Epoxiconazole & ND & 88.9 & 7.3 & 96.0 & 1.5 \\
\hline & Fluquinconazole & ND & 96.8 & 3.8 & 93.2 & 2.0 \\
\hline & Fenbuconazole & ND & 93.0 & 2.7 & 93.7 & 1.7 \\
\hline & Difenoconazole & ND & 87.2 & 2.8 & 92.0 & 2.6 \\
\hline \multirow[t]{5}{*}{ Well water } & Propiconazole & ND & 83.4 & 2.4 & 0.1 & 0.1 \\
\hline & Epoxiconazole & ND & 96.9 & 2.1 & 0.9 & 1.0 \\
\hline & Fluquinconazole & ND & 92.9 & 1.7 & 1.6 & 1.2 \\
\hline & Fenbuconazole & ND & 98.3 & 2.7 & 2.7 & 1.4 \\
\hline & Difenoconazole & ND & 86.8 & 6.0 & 1.5 & 1.7 \\
\hline \multirow[t]{5}{*}{ River water } & Propiconazole & ND & 87.3 & 1.4 & 92.9 & 1.0 \\
\hline & Epoxiconazole & ND & 91.6 & 1.5 & 96.9 & 0.8 \\
\hline & Fluquinconazole & ND & 92.7 & 3.3 & 93.3 & 2.4 \\
\hline & Fenbuconazole & ND & 90.8 & 3.0 & 94.7 & 2.9 \\
\hline & Difenoconazole & ND & 85.9 & 3.1 & 87.3 & 2.0 \\
\hline \multirow[t]{5}{*}{ Underground water } & Propiconazole & ND & 85.1 & 1.5 & 93.7 & 1.3 \\
\hline & Epoxiconazole & ND & 92.8 & 4.3 & 95.9 & 1.8 \\
\hline & Fluquinconazole & ND & 92.8 & 3.3 & 97.0 & 1.8 \\
\hline & Fenbuconazole & ND & 93.0 & 3.6 & 95.3 & 0.4 \\
\hline & Difenoconazole & ND & 85.2 & 3.2 & 92.9 & 2.8 \\
\hline
\end{tabular}

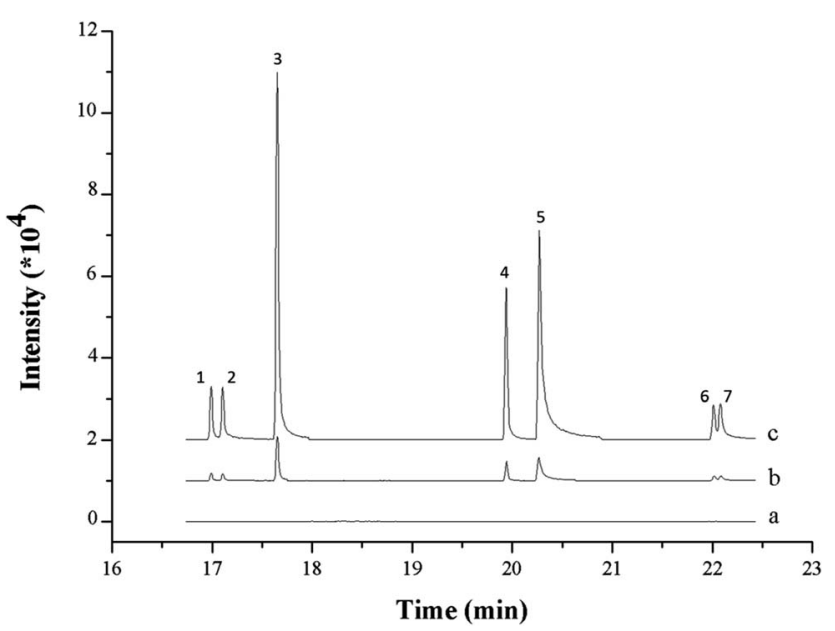

Fig. 6 TICs obtained by GC-MS/MS for the five triazole fungicides in real water samples obtained by the proposed method: river water spiked at (a) $0 \mu \mathrm{g} \mathrm{L}^{-1}$, (b) $10 \mu \mathrm{g} \mathrm{L}^{-1}$, and (c) $100 \mu \mathrm{g} \mathrm{L}^{-1}$. Peak identification: (1) propiconazole-1, (2) propiconazole-2, (3) epoxiconazole, (4) fluquinconazole, (5) fenbuconazole, (6) difenoconazole-1, and (7) difenoconazole-2.

and alkaline conditions. Thus, the $\mathrm{pH}$ of the sample solution was set at 7 in the subsequent experiments.

The ionic strength of a solution can increase the extraction efficiency of analytes. Therefore, the salinity of the solution was adjusted by adding different amounts of $\mathrm{NaCl}$ ranging from 0 to $7 \%(\mathrm{w} / \mathrm{v})$. As shown in Fig. 5H, the highest extraction performance is achieved with $1 \%(\mathrm{w} / \mathrm{v})$ addition of $\mathrm{NaCl}$ and continuously decreases with increasing addition from $2 \%$ to $7 \%$ $(\mathrm{w} / \mathrm{v})$. Based on the above results, $1 \%(\mathrm{~m} / \mathrm{v}) \mathrm{NaCl}$ was used for the MSPE process.

\subsection{Method validation and comparison}

The method was validated in terms of the linearity, limit of detection (LOD), and precision. The linearity was determined by analyzing working solutions containing the target analytes at nine concentration levels $(1,2,5,10,20,50,100,200$, and $400 \mu \mathrm{g}$ $\mathrm{L}^{-1}$ ) and plotting the peak area versus the concentration. As shown in Table 2, good linearity is achieved for the five triazoles with coefficients of determination $\left(R^{2}\right)$ ranging from 0.9915 to 0.9967. The LODs for the five analytes were calculated using a signal/noise $(\mathrm{S} / \mathrm{N})$ ratio of 3 , and the results show that the LODs range from 0.08 to $0.27 \mu \mathrm{g} \mathrm{L}^{-1}$. To validate the precision of the proposed method, six replicate ultrapure water samples spiked with $10 \mu \mathrm{g} \mathrm{L}^{-1}$ of each triazole were analyzed. The results show that the intraday precision and interday precision range from $4.04 \%$ to $7.03 \%$ and $4.43 \%$ to $9.65 \%$, respectively. All of these results indicate that the proposed MSPE method has high sensitivity and good repeatability.

To confirm the performance of the proposed method, the results from some recently reported methods for determination of triazoles were compared (Table 3). The proposed method using MMP/ZIF-8 as an adsorbent has the shortest extraction time, widest linear range, and lowest sample consumption. 


\subsection{Real sample analysis}

The developed MSPE method was successfully applied to determination of triazoles in real environmental water samples, including tap water, pond water, river water and well water. The results are given in Table 4 , and the total ion chromatograms (TIC) of the triazoles acquired from the different water samples are shown in Fig. 6. No triazole fungicides are detected in the tested water samples. Furthermore, the recovery results indicate that the current method exhibits good accuracy and possesses good utility for analysis of triazoles in real environmental water samples.

\section{Conclusion}

A novel magnetic ZIF composite has been synthesized using the $\mathrm{Fe}_{3} \mathrm{O}_{4} /$ MWCNT@PDA nanocomposite as the magnetic core and support and then used as an adsorbent for MSPE of triazole fungicides from environmental water samples. Characterization of the composite indicates that MMP/ZIF-8 has high superparamagnetism, large total pore volume, and large BET surface area, which mean that it has potential for rapid separation of triazoles from water samples. By GC-MS/MS, the proposed method exhibits high extraction efficiencies, good linearities, low detection limits, good accuracy, and good precision for separation of triazoles in water samples. This work will aid in the development of more advanced PDAfunctionalized magnetic MOFs for efficient removal of contaminants from complex matrix solution samples.

\section{Conflicts of interest}

There are no conflicts to declare.

\section{Acknowledgements}

This work was supported by the National Key Research Development Program of China (No. 2016YFD0200200), the National Natural Science Foundation of China (No. 31701695), and the Project of Risk Assessment on Vegetable Products (No. GJFP2018002).

\section{References}

1 M. Kahle, I. J. Buerge, A. Hauser, M. D. Müller and T. Poiger, Environ. Sci. Technol., 2008, 42, 7193-7200.

2 M. Komárek, E. Čadková, V. Chrastný, F. Bordas and J.-C. Bollinger, Environ. Int., 2010, 36, 138-151.

3 D. R. Ekman, H. C. Keun, C. D. Eads, C. M. Furnish, R. N. Murrell, J. C. Rockett and D. J. Dix, Metabolomics, 2006, 2, 63-73.

4 Q. Miao, J. Wang, J. Nie, H. Wu, Y. Liu, Z. Li and M. Qian, Anal. Methods, 2016, 8, 5296-5303.

5 F. Chen, Z. Song, J. Nie, G. Yu, Z. Li and M. Lee, RSC Adv., 2016, 6, 81877-81885.

6 A. C. Vieira, M. G. Santos and E. C. Figueiredo, Int. J. Environ. Anal. Chem., 2017, 97, 29-41.
7 J. Casado, D. Santillo and P. Johnston, Anal. Chim. Acta, 2018, 1024, 1-17.

8 G. A. Gómez-Ríos, E. Gionfriddo, J. Poole and J. Pawliszyn, Anal. Chem., 2017, 89, 7240-7248.

9 F. David and P. Sandra, J. Chromatogr. A, 2007, 1152, 54-69.

10 C. Herrero-Latorre, J. Barciela-García, S. García-Martín, R. M. Peña-Crecente and J. Otárola-Jiménez, Anal. Chim. Acta, 2015, 892, 10-26.

11 N. Li, H.-L. Jiang, X. Wang, X. Wang, G. Xu, B. Zhang, L. Wang, R.-S. Zhao and J.-M. Lin, TrAC, Trends Anal. Chem., 2018, 102, 60-74.

12 F. Maya, C. Palomino Cabello, R. M. Frizzarin, J. M. Estela, G. Turnes Palomino and V. Cerdà, TrAC, Trends Anal. Chem., 2017, 90, 142-152.

13 X. Cao, G. Liu, Y. She, Z. Jiang, F. Jin, M. Jin, P. Du, F. Zhao, Y. Zhang and J. Wang, RSC Adv., 2016, 6, 113144-113151.

14 C. Jiao, M. Li, R. Ma, C. Wang, Q. Wu and Z. Wang, Talanta, 2016, 152, 321-328.

15 M. Srivastava, P. K. Roy and A. Ramanan, RSC Adv., 2016, 6, 13426-13432.

16 J. Fang, Y. Yang, W. Xiao, B. Zheng, Y.-B. Lv, X.-L. Liu and J. Ding, Nanoscale, 2016, 8, 3259-3263.

17 S. Zhang, W. Yao, J. Ying and H. Zhao, J. Chromatogr. A, 2016, 1452, 18-26.

18 K.-Y. Andrew Lin and W.-D. Lee, Chem. Eng. J., 2016, 284, 1017-1027.

19 M. Zhao, Y. Xie, H. Chen and C. Deng, Talanta, 2017, 167, 392-397.

20 H. Su, Y. Lin, Z. Wang, Y. L. E. Wong, X. Chen and T. W. D. Chan, J. Chromatogr. A, 2016, 1466, 21-28.

21 X. Liu, Z. Sun, G. Chen, W. Zhang, Y. Cai, R. Kong, X. Wang, Y. Suo and J. You, J. Chromatogr. A, 2015, 1409, 46-52.

22 Z. Zou, S. Wang, J. Jia, F. Xu, Z. Long and X. Hou, Microchem. J., 2016, 124, 578-583.

23 B. Hashemi, P. Zohrabi, N. Raza and K.-H. Kim, TrAC, Trends Anal. Chem., 2017, 97, 65-82.

24 P. Rocío-Bautista, P. González-Hernández, V. Pino, J. Pasán and A. M. Afonso, TrAC, Trends Anal. Chem., 2017, 90, 114134.

25 C. Herrero-Latorre, J. Barciela-García, S. García-Martín and R. M. Peña-Crecente, Anal. Chim. Acta, 2018, 1002, 1-17.

26 Y. Xu, J. Ding, H. Chen, Q. Zhao, J. Hou, J. Yan, H. Wang, L. Ding and N. Ren, Food Chem., 2013, 140, 83-90.

27 J. Ding, Q. Gao, X. S. Li, W. Huang, Z. G. Shi and Y. Q. Feng, J. Sep. Sci., 2011, 34, 2498-2504.

28 V. Moreno, M. Zougagh and Á. Ríos, Microchim. Acta, 2016, 183, 871-880.

29 M. Khan, E. Yilmaz and M. Soylak, J. Mol. Liq., 2016, 224, 639-647.

30 Q. Zhao, F. Wei, Y.-B. Luo, J. Ding, N. Xiao and Y.-Q. Feng, J. Agric. Food Chem., 2011, 59, 12794-12800.

31 J. Ma, L. Jiang, G. Wu, Y. Xia, W. Lu, J. Li and L. Chen, J. Chromatogr. A, 2016, 1466, 12-20.

32 W. Sun, J. Shi, C. Chen, N. Li, Z. Xu, J. Li, H. Lv, X. Qian and L. Zhao, RSC Adv., 2018, 8, 10040-10056.

33 D. Che, J. Cheng, Z. Ji, S. Zhang, G. Li, Z. Sun and J. You, TrAC, Trends Anal. Chem., 2017, 97, 1-14. 
34 H. Lee, S. M. Dellatore, W. M. Miller and P. B. Messersmith, Science, 2007, 318, 426.

35 Y. Liu, K. Ai and L. Lu, Chem. Rev., 2014, 114, 5057-5115.

36 J. Zhou, P. Wang, C. Wang, Y. T. Goh, Z. Fang, P. B. Messersmith and H. Duan, ACS Nano, 2015, 9, 69516960.

37 G. Liu, L. Li, D. Xu, X. Huang, X. Xu, S. Zheng, Y. Zhang and H. Lin, Carbohydr. Polym., 2017, 175, 584-591.

38 W. Wu, L. Yang, F. Zhao and B. Zeng, Sens. Actuators, B, 2017, 239, 481-487.

39 Z. Sun, K. Xie, A. Li, I. Sinev, P. Ebbinghaus, A. Erbe, M. Farle, W. Schuhmann, M. Muhler and E. Ventosa, Chem.-Eur. J., 2014, 20, 2022-2030.
40 Z. Sun, X. Huang, F. Liu, X. Yang, C. Rosler, R. A. Fischer, M. Muhler and W. Schuhmann, Chem. Commun., 2014, 50, 10382-10385.

41 P.-Z. Li, K. Aranishi and Q. Xu, Chem. Commun., 2012, 48, 3173-3175.

42 T. Zhang, L. Lin, X. Zhang, H. Liu, X. Yan, J. Qiu and K. L. Yeung, Mater. Lett., 2015, 148, 17-21.

43 X. Liu, C. Wang, Q. Wu and Z. Wang, Anal. Chim. Acta, 2015, 870, 67-74.

44 N. Jalilian, H. Ebrahimzadeh and A. A. Asgharinezhad, J. Chromatogr. A, 2017, 1499, 38-47.

45 Y. F. Huang, Q. H. Liu, K. Li, Y. Li and N. Chang, J. Sep. Sci., 2017, 41, 1129-1137.

46 C. Liu, Y. Liao and X. Huang, J. Chromatogr. A, 2017, 1524, 13-20. 